\title{
Žohari od usmenih predaja i vjerovanja u etnotradicijama do suvremene reklame ili o tome kako su žohari na Zemlji preživjeli više od 320 milijuna godina*
}

AвSTRACT: Marjanić Suzana, Žohari od usmenih predaja i vjerovanja u etnotradicijama do suvremene reklame ili o tome kako su žohari na Zemlji preživjeli više od 320 milijuna godina (Cockroaches: From Belief Narratives to the Contemporary Commercial Practice, or How Cockroaches Have Survived on Earth for More Than 320 Million Years). "Poznańskie Studia Slawistyczne" 20. Poznań 2021. Publishing House of the Poznań Society for the Advancement of the Arts and Sciences, Adam Mickiewicz University, pp. 259-271. ISSN 2084-3011.

The first segment of the zooethical article about cockroaches, insects of the order Blattodea, who have lived on Earth for more than 300 million years (cf. Grush, 2016) and will survive the apocalypse of climate change, is based on research by Russian folklorist Aleksandr V. Gura (Гура, 2005), who gives examples of beliefs about cockroaches from the Russian ethnotradition, which I then compare with examples from the Croatian ethnotradition.In the second part of the article, I problematize the contemporary attitude towards cockroaches, starting from the literary reality of the novel Kiklop (Cyclops, 1965) by Ranko Marinković - from "Maar-commercial" ("Maar-tonfilmska reklama"), Melkior's critique of the ad-centric worldview that begins with his exit from the public toilet in the central town square. The ways in which insecticides are used against cockroaches (and other insects considered by modern civilization as pests) demonstrates that in the past at least some cultures - as Russian ethnotradition demonstrates - were far more considerate of cockroaches, as we suggested in the first part of this dichotomously structured article.

KEYwORDS: cockroaches; folkloristic research; critical animal studies; speciesism; advertisment; Ranko Marinković; Cyclops

${ }^{*}$ Tekst je sufinancirala Hrvatska zaklada za znanost (projekt IP-2019-04-5621 „Kulturna animalistika: interdisciplinarna polazišta i tradicijske prakse - ANIMAL"). 
Zar nema ničeg lijepog što se može reći o žoharima? izložba Žohari - svijet koji ostaje, Hrvatski prirodoslovni muzej, Zagreb, 2018.

Zooetički članak o žoharima, kukcima iz reda Blattodea i koje malo tko voli, a koji žive na Zemlji više od 300 milijuna godina (cf. Grush, 2016) i preživjet će apokalipsu klimatskih promjena (koja postaje sve vjerojatnija), interpolira folklorističku i kritičkoanimalističku (engl. critical animal studies) ,nišu”. Prvi segment rada temeljen je na istraživanju koje je proveo ruski folklorist Aleksandar V. Gura (Гура, 2005), koji navodi primjere o vjerovanjima o žoharima iz ruske etnotradicije, a koje onda uspoređujem s primjerima iz hrvatske etnotradicije. Ograničila sam razmatranja na ova dva slavenska primjera s obzirom na njihovu različitu etiku odnosa prema žoharima: dok su u ruskoj etnotradiciji žohari, prvenstveno crni žohari, bili cijenjeni i tretirani gotovo kao kućni ljubimci koji donose sreću i prosperitet domaćinstvu (mogli bismo ih nazvati svojevrsnim amajlijama), u hrvatskoj su etnotradiciji smatrani samo štetočinama (s čestom specističkom odrednicom - gamad), na isti način na koji ih se danas tretira. U drugom segmentu članka dopunjavam spomenutu folklorističku i etnološku perspektivu (zoofolklorističku i etnozoološku) istraživanjima provedenima iz niše kritičke animalistike, koja uključuju i pitanja prava životinja, u kojima se usredotočujem na agresivnu upotrebu insekticida, kao i na istraživanju Branislave Vičar (2018) o reklamnim strategijama koje sadrže militantne performative ubijanja žohara (npr. reklama Raid).

Ukratko, članak je napisan na sjecištu folklorističke (zoofolklorističke i etnozoološke) niše i kritičkoanimalističke niše, jer prema brojnim teoretičarima/teoretičarkama kulturoloških studija životinja, takva istraživanja moraju obuhvaćati ukupnost odnosa između ljudi i životinja (cf. Visković, $1996,11)^{1}$.

\footnotetext{
${ }^{1}$ Tekst sam napisala na temelju fragmenta mojega članka Cockroaches: From Belief Narratives to the Contemporary Visual Practice of Catherine Chalmers, or How Cockroaches Survived on Earth for More Than 320 Million Years, koji je objavljen na engleskom jeziku u časopisu Foklore Electronic Journal of Folklore, Volume 77, 2019, str. 1-20, kao i na temelju fragmenta mojega članka Reklamni bestijarij - od Marinkovićeva Zoopolisa do 'prave slovačke piletine', objavljenoga u zborniku radova Ranko Marinković - izazovi medija. Zbornik radovas 9. dana Ranka Marinkovića, Komiža, 21. - 23. rujna 2018., ur. Martina Petranović, 2020, str. 69-86. Navedena dva segmenta dovodim sada u interpretativni suodnos
} 


\section{1. Žohari u okviru folklorističkoga istraživanja: dva primjera etnotradicije - ruska i hrvatska}

Folklorističku nišu o žoharima dokumentirao je ruski filolog Aleksandar V. Gura u knjizi enciklopedijskoga formata Simbolika životinja u slavenskoj narodnoj tradiciji (prvo izdanje 1997.), u poglavlju koje tematski proučava domaće kukce - tzv. nametnike (buha, uš, stjenica, žohar). Što se tiče žohara, Aleksandar Gura zadržava se na simbolici žohara u ruskoj etnotradiciji, gdje označavaju proricatelje bogatstva i materijalnoga blagostanja. Takva se narodna vjerovanja u pravilu odnose samo na crne, a ne na riđe žohare. Prema simboličkom sustavu vjerovanja crne žohare ne istrebljuju jer se smatra da znače bogatstvo (Гура, 2005, 314-315), i nadalje, razmnožavanje ili pojavu prusaka - velikih crnih žohara - u kući smatraju osobitom srećom, odnosno prema vjerovanju - „Ako u kući u velikom broju žive crni žohari, to je pouzdan znak da čovjeku dolazi sreća" (prema Гура, 2005, 315-316). Aleksandar Gura ističe kako u navedenim vjerovanjima nailazimo na funkciju zaštitnika kućnog ognjišta, svojstvenu žoharima, kao i mnogim drugim ktonskim životinjama - gmazovima i nekim kukcima (zmiji, lasici, žabi, kornjači, krtici, crvu, pauku, cvrčku, mravima i sl.), kao što je npr. u hrvatskoj etnotradiciji uloga zaštitnice kućnoga ognjišta dodijeljena zmiji. Zabrana istrebljivanja crnih žohara najčešće se obrazlaže time da se to može nepovoljno odraziti na stoku: „C[rne] ž[ohare] ne uništavaju da bi se u kući množila stoka" (prema Гура, 2005, 315-316). U mnogim mjestima žohare ne samo da ne tamane ${ }^{2}$, već obrnuto, čak ih prenose prilikom preseljenja u novu kuću i dohranjuju, posebice za velikih blagdana, smatrajući, što više bude crnih žohara, to će se bolje razmnožavati stoka. U Vologodskoj guberniji zabilježeno je vjerovanje da je u svakome domu žoharska kraljica - žohar velik kao janje. Ako se ona pomoću vradžbina izvede iz kuće, gospodarima će umrijeti sva stoka (Totemski okrug). A ako žohari sami napuštaju kuću, to je znak neke nesreće, najčešće požara ili smrti u kući (Гypa, 2005, 315-316).

s obzirom na ovdje promatrani kontrast o dezinsekciji u etnotradicijama, s jedne strane, koje dokumentiraju da se žohari mogu ukloniti, odstraniti iz domaćinstava i neagresivnim metodama, i, s druge strane, o dezinsekciji suvremenim agresivnim insekticidima koji se temelje na militantnoj strategiji ubijanja.

${ }^{2}$ Navodim specistički glagol iz izvornika. Specističke odrednice označavam kurzivom. 
Izvan granica velikoruskoga područja zabrana istrebljivanja žohara, kao i ušiju i buha, potpuno je drukčije naravi i najčešće vezana s opasnošću osvete čovjeku od tih ili drugih kukaca (isto obrazloženje odnosi se na zabranu ubijanja lasice, zmije te nekih drugih gmazova i kukaca). Tako Guculi smatraju da se žohare ne smije ubijati zato što će njihova subraća iz osvete padati u jelo onomu koji ih je uvrijedio (Гура, 2005, 315-316). Ukratko, do sada je što se tiče proučavanja uloge žohara u slavenskim tradicijama jedino Aleksandar Gura proveo sustavno istraživanje folklorističkih zapisa; npr. ulogu žohara ne pronalazimo u Đorđevićevoj knjizi Priroda $u$ verovanju i predajama našega naroda (1958), što je prva sustavna knjiga, enciklopedijskoga formata i u dva toma, o životinjama u južnoslavenskim etnotradicijama.

Što se tiče hrvatskoga folklorističkoga materijala, etnograf Milan Lang (1863. - 1953.) u monografiji Samobor - narodni život i običaji za Samobor (nedaleko od Zagreba) ${ }^{3}$ zapisuje da Samoborci slabo poznaju kukce po imenu, a od žohara navodi sljedeće vrste: švaba - Blata tedescha i žohar Blatta orientalis (Lang, 1992, 50-51; cf. sliku 1). Navedeni vrlo kratak zapis svjedoči da Lang razlikuje švabe i žohare, što u hrvatskom i srpskom jeziku označava istoga kukca (srp. bubašvaba; hrv. žohar). Nadalje u poglavlju Priroda navedene monografije Milan Lang zasebno piše o životinjama i kukcima. U poglavlju Životne potrepštine uvodi zasebno potpoglavlje, specističkoga suodnosa prema kukcima; potpoglavlje naslovljava Tamanjenje životinja i gamadi, pri čemu detaljno navodi kako se ubijaju (tamane) žohari i švabe. Upućuje na to da je potrebno u visoku zdjelu uliti nešto staroga piva, a naokolo uz rub posude prisloniti drvca ili trijeske. Žoharima miriše pivo, ući će u posudu, opit će se i neće više moći izaći. „Neki im opet nastavljaju po rupama ovu hranu: trećinu bijela brašna, trećinu stučena sladora i trećinu boraksa, sve dobro smiješano. Od toga - kažu poginu svi žohari i švabe" (Lang, 1992, 178). Dakle, pod žoharima Lang podrazumijeva orijentalnoga žohara, crnoga žohara, za kojega se obično navodi da ostavlja neugodan miris na površinama kojima prolazi. Nadalje, za razliku od navedena dva tradicijska načina uništavanja, tamanjenja žohara, danas se kao načini njihova uništavanja preporučuju orošavanja

${ }^{3}$ Monografija je objavljivana najprije u Zborniku za narodni život i običaje Južnih Slavena, 1911. - 1914.; reprint: 1992. i 2009. 
bilica (Locusta viridissima), klop (Ixodes ricinus), Komarec (Culex pipicus), kojnska muha (Hippobosca equina), kosëc (Lebellula depressa)1, kršel, krvava vuš (Schizoreura lanigera), kucna baba (Pentatoma grisca), metal (uopée sviki), molci (T'inea), mrâvec (Formica), muha (Musca domestica), obad (Tabanus bovinus), osä (Vespa vulgaris), pâvuk (Tenegaria domestica)2, rogác (Lucanus cervus), rogủ (sićušni kukčić, živi a bras̆na i mekinjama, a poslije zalazi i u zito), stenica (Aconthia lectularia), strižavka (Fornicula auricularia), stršen (Vespa crabro), svilec (Bombyx mori; od njega neki goje gasjenice, koje zovu "kakei"), škorpijon (Scorpio europaeus), šosttar (Cimex ornatus), španišmuha (Litta resicatoria). švaba (Blatta tedescha), têkuti (Mallo. phaga), vinske mušice (drže so oko vina i vinskoga tropa), vrlëc (Gryllotalpa vulgaris), vuš (Pediculus capitis; od njih su gnide), žižek (Calandra granaria) ${ }^{3}$, žohar (Blatta orientalis), žuti metul (Rhodoceras rhamni).

Slika 1. Stranica iz monografije o Samoboru Milana Langa koja dokumentira razlikovnu odrednicu između švaba - Blata tedescha i žohara - Blatta orientalis

površina insekticidom na bazi deltametrina, piretrina, fipronila te aplikacijom insekticidnog gela s atraktantom, postavljanjem lovki s atraktantom (Blatta orientalis - crni žohar). Istina, alternativa opasnim i agresivnim insekticidima postoji, pa alternativne prakse bliske eco-friendly odnosima prema okolišu preporučuju za odstranjivanje paukova i žohara miris eteričnog ulja paprene metvice i octa. Navedenu mješavinu pauci i žohari ne podnose ${ }^{4}$.

Za razliku od navedenih folklorističkih zapisa s terena, koji razlikuju žohare i švabe, biolog Kišpatić dvadesetak godina ranije od spomenuta Langova zapisa u zoološkoj knjizi pod nazivom Kukci piše o žoharu ili Švabi (Blatta, Periplaneta orientalis, Küchenschabe, Schwabe), a „znanstveni” opis započinje specistički - ,vrlo je oduran i dosadan stanar po naših kućah” (Kišpatić, 1887, 188). Pritom navodi kako se možemo „riješiti” švaba, slično Langu, no ističe i alternativu prirodnom načinu ,uklanjanja” - potrebno je nabaviti ježa: „Jež jede vrlo rado švabe, pa nam i on može pomoći, da kuću od švaba očistimo" (Kišpatić, 1887, 190). Međutim, za razliku od Langa, Kišpatić uvodi razliku između žohara/švaba

${ }^{4}$ Cf. https://www.24sata.hr/lifestyle/genijalan-trik-kako-se-rijesiti-zohara-i-paukajednom-zauvijek-491253. 
i rusa (Blatta germanica, Deutsche Schabe, Russe, Blatta tedescha), za kojega navodi da je najbliži rođak švabama (žoharima). Bilježi predaju da ga u Rusiju zovu prusom jer misle da su ga vojnici donijeli poslije Sedmogodišnjega rata iz Njemačke s obzirom na to da ga u Petrogradu prije toga nisu poznavali. I nadalje zapisuje: „U Austriji opet misle, da su ga prenijeli radnici s ruske granice $u$ češke staklane, odakle da se je po Austriji raširio. Bilo kako mu drago, samo su rusi danas gotovo po svem svijetu rašireni" (Kišpatić, 1887, 190) $)^{5}$. Što se tiče opisa, ističe da su rusi sitniji od švaba, da su zemljastožute boje te da ruse tamane na isti način kao i švabe, a bilježi i nešto „uljudniji”, „humaniji” način uništavanja rusa: „Kako rusom jako škodi nagla promjena topline, to preporučuju, da se zimi na dulje vremena otvore prozori i vrata, jer da na taj način češki seljaci čiste svoje kuće od rusa" (Kišpatić, 1887, 191) ${ }^{6}$.

\section{Specistička reklama o kukcima: nature wars}

U ovome dijelu članka problematiziram suvremeni odnos prema žoharima, pri čemu krećem od književne zbilje Marinkovićeva romana Kiklop (1965) - od Maar-tonfilmske reklame, Melkiorove kritike centralnoreklamnoga pogleda na svijet koja započinje njegovim izlaskom iz javnoga WC-a na središnjem gradskom trgu, vjerojatno dvokatne civilizacije, kako je Krleža označio Zagreb u Davnim danima. Registar tonfilmskih reklama započinje Radionom, reklamnim sloganom „Radion pere sam”, a završava još jednom higijeničarskom reklamom - o Prvom hrvatskom zavodu za sjajne pogrebe (Marinković, 1981, 7-8), što podsjeća na metonimiju Krležinog Velikog meštra sviju hulja. Pritom se negdje u sredini enumeracije centralnoreklamnoga pogleda na svijet pripovjedač zaustavlja na kontrapunktu između tonfilmskih reklama i usmene reklame slijepoga prosjaka koji reklamira končane vezice kao dokument umiranja usmene reklame.

\footnotetext{
${ }^{5}$ Primjerice, u češkoj etnotradiciji savjetovalo se otvaranje prozora kako bi se riješili žohara tijekom zimskih mjeseci (Kišpatić, 1887, 190).

${ }^{6}$ Od kazivačica Agate Mavrek i Nade Bregović iz Ivanca doznajem kako su manji žohari znali ulaziti u uši djeci (kao i strige, ostrige, dzige...) i onda su ih istjeravali mlijekom iz dojke, „zadajali” - žene su štrcale djeci mlijeko iz dojki u uši. Kazivanje zabilježeno 5. rujna 2020 .
} 


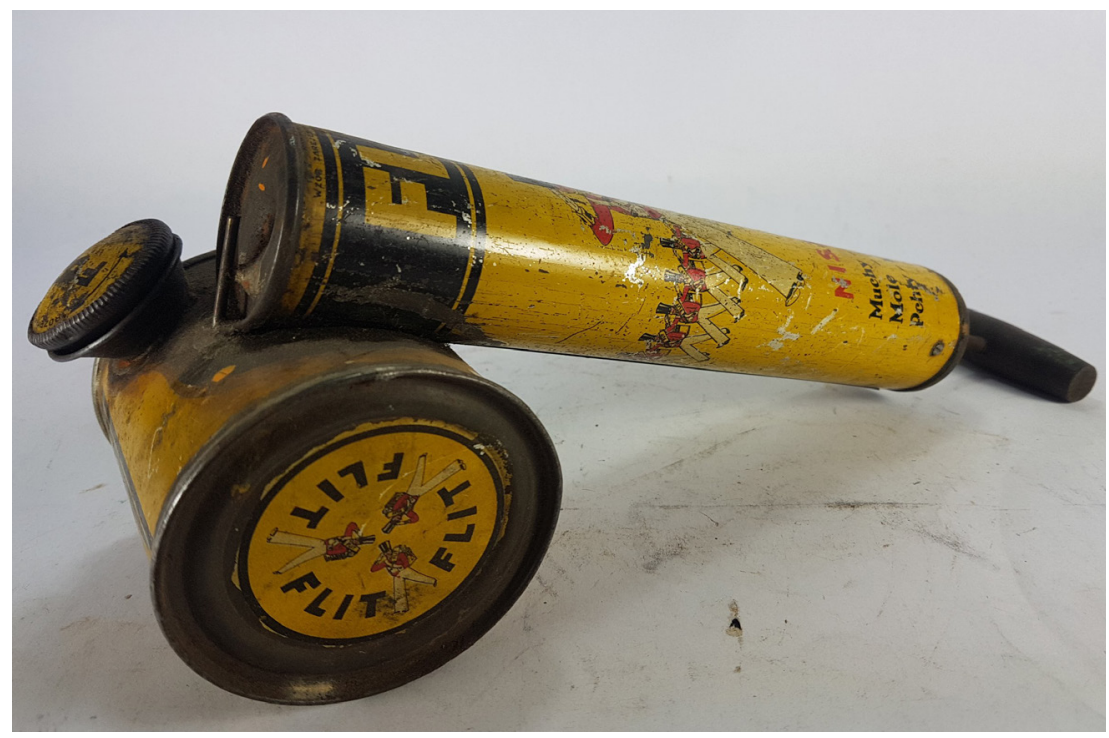

Slika 2. Ranko Marinković: Kiklop - „Flitov grenadir naoružan čuvenom Flitovom štrcaljkom"8. Militantni dizajn insekticida

Zaustavljam se na reklamnom bestijariju, specističkoj reklami o ubijanju silne horde žohara, buha, stjenica i ostale strašne ,gamadi”, formacije moljaca i muha uz pratnju brzih eskadrila komaraca, a uništavanje te horde i formacije radi Flitov grenadir, naoružan čuvenom Flitovom štrcaljkom (Marinković, 1981, 8; cf. sliku 2), što je primjer dokumentarizma reklame o našem specističkom odnosu prema životinjama, u ovom slučaju kukcima, koji je nekoć bio drugačiji.

Onda navali silna horda žohara, buha, stjenica i ostale strašne gamadi, a gore iznad horde guste formacije moljaca i muha uz pratnju brzih eskadrila komaraca... Kad odjednom začuje se teški topot kopita, a malo zatim dojuri na konju Flitov grenadir naoružan čuvenom Flitovom štrcaljkom i začas bojno je polje prekriveno izginulom vojskom (gamadi) (Marinković, 1981, 7-8).

${ }^{7}$ Fotografija preuzeta s internetske stranice: https://archiwum.allegro.pl/oferta/stary-rozpylacz-owadobojczy-flit-reklama-i7351231716.html. 
Nekoliko mi je osoba potvrdilo da je riječ o insekticidu koji se koristio i na/u Marinkovićevu Visu ${ }^{8}$. Mark L. Winston $(1997,47)$ isto kao i Marinković zamjećuje kako i danas insekticidi nose militarističke nazive kao npr. Ambush ili Sidekick .

Navedenom reklamom, koja je pritom jedina zooreklama u književnim svjetovima Kiklopa, Marinković dokumentira naš specistički odnos prema našim najznačajnijim drugima, kako je životinje (s obzirom na evolucijski kontinuitet, u prvom redu - čovjekolike majmune) odredio primato$\log$ i antropolog Craig Stanford ${ }^{9}$. Tim prvim stranicama koje su posvećene centralnoreklamnom pogledu na svijet Marinković kao da navodi misao Gillesa Lipovetskog o tome da se homo felix ipak ne podudara s homo consumansom, consumatorom (Lipovetsky, 2008, 117).

Navedena reklamna eskapada koju Melikor zamjećuje dokumentira rast kapitalizma kao što ga je i Krleža dokumentirao u svojim Davnim danima (s vremenskim horizontom 1914. - 1921./22.) enumeracijom stranih banaka, ulogom stranoga kapitala. Naime, svjetski poznat proizvođač sapuna Georg Schicht 1922. godine u vlasništvo preuzima do tada lokalnu osječku radionicu sapuna Samuela Reintza te u pogonima nove tvornice nastaje sredstvo za pranje tkanina Schichtov (današnja osječka Saponia) Radion, „promidžba kojeg će na području cijele tadašnje Kraljevine SHS (doslovno od Vardara do Triglava), pokrenuti jednu od prvih cjelovitih reklamnih kampanja" (Benić, 2010) ${ }^{10}$. Melkior s podsmijehom gleda animirani film projiciran na središnjem zagrebačkom trgu, a koji na ilustrativan način

${ }^{8}$ Npr. Dobrila Cvitanović, predsjednica Ogranka Matice hrvatske u Visu, rekla mi je da se u njezinom djetinjstvu govorilo da ,za raskužiti kuću da ćemo naflitat kuću protiv te gamadi" (zabilježeno 22. rujna 2018).

${ }^{9}$ Među prvima je o reklamama u Marinkovićevu Kiklopu pisao Radivoje Mikić (1988, 239-241), no on se ne zaustavlja na navedenoj specističkoj reklami. Nakon njega Renate Hansen-Kokoruš (2004, 77-87) reklame Ranka Marinkovića kontekstualizira zenitističkom nišom.

${ }^{10}$ Kao što navodi Ana Sladetić, „Najviše proizvoda koji se reklamiraju na pronađenim plakatima (Elida proizvodi, Vim, Radion, Sargov Kalodont) nastalo je u tvrtki Georga Schichta. Današnju kemijsku industriju Saponia, koja se bavi proizvodnjom deterdženata te proizvoda za osobnu higijenu i sredstava za kućansku i industrijsku čistoću, osnovao je 1894. godine Samuel Reinintz, a prvi njezin naziv bio je Obrtnička radionica za proizvodnju sapuna. Radionica se 1919. godine povezuje sa svjetski poznatom tvrtkom Georga Schichta. Tvrtka 1922. najprije preuzima samo pogone u zakup, da bi 1928. godine došlo do potpunog stapanja" (Sladetić, 2016, 75). 
promovira reklamnu strategiju „Radion pere sam”"11 - prljave košulje uplašeno hodaju prema uzavrelom kotlu u koji je umiješan Radion, sa strahom u očima uskaču u uzavrelu vodu te se tada događa čudo - potpuno bijele, neoštećene i ponosne izlaze iz kotla, pjevajući u slavu njihovog sapunskog junaka (cf. Mikić, 1988, 239-241). Navodim kako je prije nekoliko godina u Muzeju Slavonije pronađena zajedno s ostalim reklamnim filmovima Schichtove tvornice i navedena „Smotra rublja”, čiji sadržaj uvelike sliči Melkiorovoj paranoidnoj viziji. I dok se kraj romana otvara prema heterotopiji zoološkoga vrta - Zoopolisa, kao jedinoga human(itarn)oga mjesta, uvodni dio romana orijentiran je na nemjesto reklama vrlog novog svijeta.

Nadalje, što se tiče niše prava životinja, navela bih rad slovenske kolegice Branislave Vičar, koja iz kritičkoanimalističke perspektive govori o specističkoj reprezentaciji žohara kao i ostalih kukaca u reklamama te navodi primjer reklame Raid za uništenje kukaca koje obično u specističkoj kulturi doživljavamo kao nametnike. Uostalom, i u folklorističkoj niši zamjetni su specistički glagoli koji se koriste za žohare - riješiti se, istrijebiti, ubiti, uništiti... Pritom autorica zamjećuje kako su u počecima nastanka oglasi za insekticide u pravilu bili dvaput duži nego što su to suvremene reklame u kontekstu onoga što se zove vizualni preokret (visual turn). Tako B. Vičar kao primjer navodi da originalni oglas za Raid traje 1 minutu, a dužina oglasa Raid Television Commercial iznosi 29 sekundi. Isto tako ističe da se suvremene reklame sastoje od više strukturalnih jedinica jer su za njih karakteristični kratki kadrovi koji se brzo izmjenjuju. Zatim slijedi interpretacija iz animalističke niše jedne takve reklame: prva scena prikazuje kukce različnih vrsta u strahu od Raida. Za ilustraciju autorica prilaže transkripciju svih pet kadrova prve scene, od kojih ću ovom prigodom navesti samo tri.

\footnotetext{
${ }^{11}$ Riječ je ujedno o segmentu romana u kojemu se prvi put pojavljuje riječ strah, i to u tautologijski pojačanoj sintagmi ,panični strah”: „Pojavi se zatim kuća jadna i prljava, naherena krova, izvaljenih vrata, a iz njenih prozora u paničnom strahu iskaču zgužvane i musave košulje, sablasna torza bez glave i nogu. Uz muziku dance macabra vuku se bolesne žrtve nečistoće prema kotlu na vatri u kome nestrpljivo kipi gusta bijela pjena. S usidjeličkim nepovjerenjem, oklijevajući još na samom rubu kotla (boje se da ih ne nasamare) skaču košulje u pjenu... i gle, nepovjerenje je bilo posljedica glupe predrasude, jer evo kako jedna za drugom blistavo bijele izlaze iz kotla i marširajući u redu pjevaju oduševljeno «Radion pere sam»" (Marinković, 1981, 5-6).
} 
Kadar 1. Total mreže na prozoru, kroz rupu na mreži ulijeće muha koja postupno ulazi u krupni plan. Muha vikne.

Muha: „RAAAIIID je tu!!!”

Kadar 2. Krupni plan prepune posudice za šećer, prati ga srednji plan mrava koji skače iz šećera, vikne te se iscrtanim ,ljudskim” rukama hvata za glavu. Pozadina je prazna, horizontalne linije pokazuju da se radi o zidu.

Mrav: „RAAAIIID!!!”

[...] Kadar 5. Snimak kukca iz blizine, kukac u strahu viče i bježi.

Žohar: „RAAAIIID!!!”

$[\ldots]$

Pojavljuje se veliki insekticidni oblak koji zauzima cijeli prostor, a u njemu natpis: „SVE VRSTE INSEKATA IZNUTRA”.

[Zvuk spreja.]

Glas pripovjedača: Da, Raid ubija muhe, komarce, žohare, mrave - sve vrste insekata iznutra (Vičar, 2018).

Zamjetno je da starije reklame engleskoga jezičnoga područja koriste specistički glagol to kill, dok novije reklame ublažavaju naš specistički terminatorski odnos prema žoharima te rabe ,blažu” varijantu - glagol to beat, no koji jednako dobro demonstrira naš specizam prema kukcima.

\section{Zootički zaključno o žoharima - svijetu koji ostaje u binarizmu čisto-opasno}

Načini na koje se insekticidi koriste protiv žohara (i drugih kukaca koje suvremena civilizacija smatra štetočinama) demonstrira da su u prošlosti barem neke kulture - kao što pokazuje ruska etnotradicija - bile daleko obzirnije prema žoharima, kao što smo sugerirali u prvome dijelu ovoga dihotomno strukturiranoga članka. Naime, nastojala sam kroz vremensku lentu na odabranim primjerima dokumentirati kako se danas u suvremenom tretmanu prema žoharima zatomio magijski odnos prema njima kao sustvorenjima, koji je postojao primjerice u ruskoj etnotradiciji, kako je sustavno dokumentirao Aleksandar V. Gura, i pritom jednako se tako može i u širim primjenama, a ne samo u bioetičkoj permakulturi, sugerirati etnotradicijsko uklanjanje žohara za razliku od dominirajućega militantnoga koje se provodi agresivnim insekticidima. Istina, neki dezinsektori ne koriste militantna sredstva za uništavanje žohara. Tako čikaški dezinsektor 
Hugo Hartnack, autor vodiča za suzbijanje štetočina, preporučuje jednostavne domaće zamke za žohare bez otrova s rampama koje kukce vode u staklenku s mamcem koju čini omiljena hrana žohara. Neki dijelovi njegova priručnika o žoharima sugeriraju kemikalije samo kao „hitne mjere" (Day Biehler, Cronon, 2013, 361). Ponavljam uspješnu alternativnu eco-friendly praksu koja preporučuje za odstranjivanje paukova i žohara miris eteričnog ulja paprene metvice i octa s obzirom na to da tu mješavinu pauci i žohari ne podnose.

Militantno istrebljivanje žohara očito je rezultat urbanizacije postindustrijske revolucije i odvojenosti od konteksta poljoprivrede - uvođenje novih kulturnih normi higijene/čistoće pomoću kojih, da se poslužimo strukturalnom dihotomijom čisto-opasno Mary Douglas (2004, 27-54), sve što je povezano s puzanjem stavlja se u kontekst moguće opasnosti za ljudsku vrstu. U europskoj povijesti promjene u higijenskim navikama nisu bile potaknute željom za čistoćom, već njihovom atraktivnošću i trendovima. Devetnaesto stoljeće se navodi kao stoljeće velikih promjena $\mathrm{u}$ higijenskim pitanjima. $U$ to je vrijeme vrlo malo ljudi imalo kupaonicu u današnjem smislu te riječi; nužnik (toalet, zahod) obično se nalazio odvojeno, dok se do sredine 20. stoljeća kupalo u grijanoj sobi (kuhinja ili, češće, spavaća soba, koristeći korito i umivaonik), često u nazočnosti drugih osoba (sluga ili rođaci; cf. Sladetić, 2016, 131).

Kulturni animalist Boria Sax navodi da je ,[naše] razumijevanje životinja toliko usko povezano s našim vlastitim konceptima sebe kao ljudima, da se teško možemo nadati da ćemo ih potpuno razdvojiti. Reprezentacije životinja uvijek su sadržavale projekcije naših najdubljih nada, strahova i težnji" (Sax, 1990, 146; cf. Boxer, 2003; Schweid, 1999; Copeland, 2003; Žohari - svijet koji ostaje, 2018; Marjanić, 2017). Nikola Visković u svojoj zooetičkoj knjizi iz 1996. godine ističe kako je u suvremenom holokaustu životinja izuzetno malo vrsta kojima tehnološka civilizacija zasad pogoduje, a to su prije svega žohari, zatim štakori, golubovi, vrapci, galebovi (Visković, 1996, 309). Spominje i projekt domestikacije žohara, o čemu je pisao npr. M. Girard u knjizi La domestication des blattes (Paris, 1877) (Visković, 1996, 278). Jednako tako podsjeća na knjigu Dirka Maxeinera i Michaela Mierscha Öko-Optimismus (Düsseldorf, 1996), gdje iznose podatke zanimljive za studije koje nastaju na prožimanju urbanih studija i (kritičke) animalistike da je u Frankfurtu npr. zabilježeno oko 2000 vrsta 
žohara, a pored njih i 102 vrste ptica, 14 vrsta vodozemaca i 33 vrste mrava te da veliki europski gradovi u prosjeku udomljuju oko 18000 zoovrsta (Visković, 1996, 227).

No srećom, žohari pripadaju svijetu koji ostaje, kako je i glasio naziv iznimne izložbe u zagrebačkom Hrvatskom prirodoslovnom muzeju (Žohari - svijet koji ostaje, 2018.), prve naše zooetičke izložbe o žoharima ${ }^{12}$, izložbe o kukcima koje malo tko voli, no koji će ostati na planetu i kada ljudska vrsta izumre, nakon mogućega, sasvim realnoga nuklearnoga rata ili pak globalne pandemije (ne pandemije COVID-a 19).

\section{Literatura}

Benić, K. (2010). Radion pere sam. https:/www.tportal.hr/vijesti/clanak/radion-pere-sam-20100715. 1.10.2020.

Blatta orientalis - crni žohar. http://www.adlibitum.hr/blatta-orientalis-crni-zohar/. 24.08.2018.

Boxer, S. (2003). Cockroaches as Shadow and Metaphor: An Artist Began Chilling and Decorating Bugs, But Moved On to Depicting Their Executions. „The New York Times". https://www.nytimes.com/2003/05/08/arts/cockroaches-shadowmetaphor-artist-began-chilling-decorating-bugs-but-moved.html. 24.08.2018.

Copeland, M. (2003). Cocroach. London: Reaktion Books.

Crni žohar. http://www.id90.hr/kukci/zohari/crni-zohar. 4.03.2019.

Day Biehler, D., Cronon, W. (2013). Pests in the City: Flies, Bedbugs, Cockroaches, and Rats. Washington: University of Washington Press.

Douglas, M. (2004). Čisto i opasno: antropološka analiza pojmova nečistoće i tabua. Zagreb: Algoritam.

Grush, L. (2016). The Verge Review of Animals: The Cockroach, the Perfect Organism. https://www.theverge.com/2016/1/17/10777040/cockroach-animal-review. 24.08.2018.

Gura, A. V. (2007). Simbolika životinja u slavenskoj narodnoj tradiciji: domaći kukci - nametnici (buha, uš, stjenica, žohar). U: Kulturni bestijarij. Ur. S. Marjanić, A. Zaradija-Kiš. Zagreb: Institut za etnologiju i folkloristiku-Hrvatska sveučilišna naklada, str. 99-124.

Hansen-Kokoruš, R. (2004). Avangardni preteksti u Marinkovićevu djelu. U: Komparativna povijest hrvatske književnosti. Europski obzori Marinkovićeva opusa.

${ }^{12}$ Autorica i koncept izložbe: dr. sc. Iva Mihoci. Autori izložbe i kataloga: Iva Mihoci, Petar Crnčan, Vlatka Mičetić Stanković i Mateja Jagić. 
Zbornik radova VI. sa znanstvenog skupa održanog 29. i 30. rujna 2003. godine u Splitu. Ur. M. Tomasović et al. Split: Književni krug, str. 77-87.

Kišpatić, M. (1887). Kukci. Prirodopisne crtice. Knjiga II. Zagreb: Matica hrvatskaTisak Dioničke tiskare.

Lang, M. (1992). Samobor. Narodni život i običaji. Reprint. Samobor: „Zagreb”, Poduzeće za grafičku djelatnost.

Lipovetsky, G. (2008). Paradoksalna sreća. Ogledi o hiperpotrošačkom društvu. Zagreb: Antibarbarus.

Marinković, R. (1981). Izabrana djela II. Kiklop. Pet stoljeća hrvatske književnosti, knj. 137. Zagreb: Nakladni zavod Matice hrvatske.

Marjanić, S. (2017). The Anthropology of Animals - Paradox and/or Necessity. U: What to Do with Folklore? New Perspectives on Folklore Research. Ur. M. Golež Kaučič. BASIS, knj. 9. Trier: Wissenschaftlicher Verlag Trier, str. 123-139.

Mikić, R. (1988). Postupak karnevalizacije: Uvod u poetiku Ranka Marinkovića. Beograd: Filip Višnjić.

Sax, B. (1990). The Frog King. On Legends, Fables, Fairy Tales and Anecdotes of Animals. New York: Pace University Press.

Schweid, R. (1999). The Cockroach Papers: A Compendium of History and Lore. New York: Four Walls Eight Windows.

Sladetić, A. (2016). Vizualni ogledi o čistoći: zid kao mjesto, prostor i sjećanje. [Neobjavljena doktorska disertacija]. Zagreb: Akademija likovnih umjetnosti.

Vičar, B. (2018). Diskurzivna konstrukcija kukaca u televizijskim oglasima: multimodalna analiza. [Neobjavljen rad, u tisku].U: Bestijarij hrvatske etnokulture: leksikon [radni naslov leksikona projekta IP-2019-04-5621 „Kulturna animalistika: interdisciplinarna polazišta i tradicijske prakse - ANIMAL", Hrvatska zaklada za znanost].

Visković, N. (1996). Životinja i čovjek. Prilog kulturnoj zoologiji. Split: Književni krug.

Žohari - svijet koji ostaje. Autorica i koncept izložbe: I. Mihoci. Autori izložbe i kataloga: I. Mihoci, P. Crnčan, V. Mičetić Stanković i M. Jagić. Zagreb: Hrvatski prirodoslovni muzej, 2018.

Winston, M. L. (1997). Nature Wars. People vs. Pests. Cambridge, MassachusettsLondon: Harvard University Press.

Гура, А. (2005). Симболика животиња у словенској народној традищији. Београд: Бримо-Логос-Александрија.

Ђорђевић, Т. Р. (1958). Природа у веровағу и предағу намега народа, II књига. „Српски етнографски зборник” књ. LXXII.

[Gura, A. (2005). Simbolika životinja u slovenskoj narodnoj tradiciji. Beograd: BrimoLogos-Aleksandrija.

Đorđević, T. R. (1958). Priroda u verovanju i predanju našega naroda, II knjiga. „Srpski etnografski zbornik" knj. LXXII]. 